\title{
WOUND-DRESSERS AND HOUSE CALLS: Medical Representations in Whitman and Williams
}

\author{
ROBERT LEIGH DAVIS
}

WATCHING A BOATLOAD of sick and wounded soldiers unload near Annapolis, at the end of the war, Whitman asks:

Can those be men - those little livid brown, ash-streak'd, monkey-looking dwarfs? - are they really not mummied, dwindled corpses? They lay there, most of them, quite still, but with a horrible look in their eyes and skinny lips (often with not enough flesh on the lips to cover their teeth. $)^{1}$

Deep suffering, as Whitman emphasizes throughout the war years of Specimen Days, dehumanizes and makes unrecognizable the physical body of the sufferer. Whether what results is a "monkey-looking dwarf," or a "heap" of arms and legs (32), or random "bones, tufts of hair, buttons, fragments of clothing" (114), the consequence of injury is radical incoherence. The wounded body presents itself to Whitman (as it will a generation later to William Carlos Williams) as insistently different from the poet's own body, and the encounter of the healer with his patient, the nurse with his wounded soldier, comes to define the encounter with the alien or the stranger, with whatever stands against and apart from the self. Medical attention and care begin with the recognition of this difference. When Whitman asks, "Can those be men?" (100); "[I]s this indeed humanity?" (46); "Who are you my dear comrade?" ("A Sight in Camp in the Daybreak Gray and Dim"); ${ }^{2}$ and when Williams's patients themselves ask, as they do throughout the medical stories, "What's the matter with me?"; the questions assume a disturbing awareness of difference and urge a response that might diminish it. It is this response to difference that distinguishes the medical representations of Whitman and Williams. For Whitman, medical attention restores the coherence and social interconnection lost in deep injury. The disfigured patient grows familiar through the attentions of his nurse; the monkey dwarf becomes a man. As Whitman cares for his patients, we are led to see that what is done to the body of the suffering patient in a hospital is a version of what is done to the representation of the suffering patient in a poem. Dressing a wound, and writing a poem about dressing a wound, I will argue, are significantly equivalent acts in Whitman's imagination: both re-invest the body with the legible signs of material culture, and so rescue it from the incoherence and "utter strangeness" (50) of the wound. 
In Williams's medical stories, on the other hand, the otherness of the patient stubbornly resists tactics of familiarity. Where Whitman seeks to reconnect his wounded patients to coherent patterns of meaning, it is the interruption of these patterns that concerns Williams. The patients in his work are less passive, less accommodating - like the child in "The Use of Force," they can knock your glasses off. But by such gestures of resistance they call attention to the distortion, however favorable, in the doctor's own vision. Because they are unassimilated and unfamiliar, and because they remain so, the patients in Williams's work make possible "the release from ... fixities" 3 that is the constitutive act of his poetic imagination.

In both Specimen Days and Drum-Taps, Whitman represents the wounded soldiers in terms of diminishment and loss. The body has been literally cut down from its earlier stature and wholeness by the time it enters the Washington hospitals, and the amputation surfaces again and again in Whitman's writing not only as a cultural symbol of the war - "the United States . . . split, crippled, and dismember'd" (93) - but as the most vivid example of the diminishment entailed in all injury, and registered in a number of forms of loss. The faces of Whitman's patients lack feature and expression: they are "pallid," "emaciated," "bloodless," "colorless," or "white." Eyes are "dulled," "glassy," "empty," and "blank." The soldiers have lost friends (42), relatives (42), memory (49), desire (51), money (50), appetite (42), their own names (49), and, significantly, they react to pain without language: "You may hear groans or other sounds ... but in the main there is quiet - almost a painful absence of demonstration" (41-42). Whitman's expression, "painful absence," becomes a kind of redundancy in the descriptions of these soldiers, for the effect of their pain is to evacuate their world. ${ }^{4}$

The sense of diminishment in Whitman's hospital writing, however, is not limited to these forms of loss. The more damaging effect of the patient's suffering is that it blocks out from an observer's attention any object but itself, and leaves the soldier identified, and identifiable, only in terms of his wound, only in terms, then, of his radical difference from the "perfection of physical health" (52) of his witness. At those moments when Whitman's description of a hospital scene tends toward the bare listing of wounds - as in "The Wound-Dresser," for instance, when the speaker, moving through a hospital tent, sees "a crush'd head," "the stump of the arm," "the amputated hand," "the perforated shoulder," "the foot with the bullet wound," but sees each wound in isolation from the soldier, as a kind of metonomy for the soldier - Whitman shows that what the patient has lost, in fact, is a self. Consider how, in a radical emphasis on subtraction, the wound in "Calhoun's Real Monument" is made to stand for the unseen, unrepresented soldier: "In one of the hospital tents for special cases ... I sat today tending a new amputation" (109). By diminishing and fragmenting the body, the representation resembles the effect of the wound. Injury renders the body unrecognizable and inhuman not only by creating a physical loss - a bullet hole where skin 
used to be, a stump where a hand used to be, a white face where color and expression used to be-but also by erasing the familiar signs of personality and selfhood, eliminating the distinguishing details, "the patient's specific address" (69), that individualize and locate that patient in the world. The soldier's anonymity emerges in these passages as the consequence and social equivalent of the physical wound. Both forms of loss are imaged in terms of emptying - the body of blood, of limbs, of color, and the self of a name, a hometown, a history, a family, a style of physical and verbal expression.

The passages of description in Whitman's work may then be seen as a response to this anonymity. In the paragraph in Specimen Days beginning "W. H. E., Co. F., 2d N.J." (50), for example, the abbreviations of the patient both display a reduction of identity and urge the descriptive expansion that follows. To the cut-down and punctuated title, Whitman adds richly specific and detailed information: his disease is pneumonia; he lay sick at the hospital below Aquia creek; he was detailed to go there as a nurse; he is a widower; he has children; he likes to drink green tea. There is a kind of linguistic generosity in these descriptions, a lending out of the poet's voice and language in order to add back in what has been emptied out and diminished.

The effect of Whitman's voice then is to relocate the wounded soldier within social space. "W. H. E." regains a social self through such specifying description: he is reconnected to a family relationship, a military history, a taste for tea. Like the other "appropriate gifts" of Whitman's work as a nurse, his language reinvests the soldier with familiar signs. Possessing nothing, desiring nothing, saying nothing, the wounded soldier remains outside the web of tastes, desires and possessions that articulate community membership even after he is brought into its enclosing institutional walls. Whitman's attention to the "things wanted by one patient or another" (82)-a list that includes "socks," "combs," "horehound candy," "a little tart jelly" - signals the patient's return to familiar needs and desires, and so signals, as well, his return to social identity.

These responses to suffering in Specimen Days are keyed to a more general pattern in Whitman's work in which the act of caring is rendered as an act of covering over or filling in an exposed surface. Covering a wound with a cloth bandage, covering a corpse with a grave and marker, covering an open field with the walls and roof of a hospital tent: these actions metaphorically share in the central act of coverage in these works-covering a blank page with written text. In each case the material artifact stands as a sign of social participation and coherence. The wound-dressing, the gravestone, the hospital, and the poem each inscribe a space emptied of human content with a code that familiarizes and reclaims it. In the clearest demonstration of this technique in Drum-Taps, Whitman invests an anonymous soldier with the most familiar and richly determined of signs - "the face / of the Christ himself" ("A Sight in Camp," 307). By re-signifying the space of the wound, or the corpse, or the battlefield - by dressing that space in social signs - the arti- 
fact makes it legible, subject to coherent ways of seeing and reading. The cloth bandage not only re-connects the split edges of an open wound, and so restores the body to a kind of individual coherence, but at the same time, as a sign of public intervention, the bandage encloses the soldier within the practices and procedures of medical discipline, and so restores the body to a kind of social coherence. This of course will not be the last time that a writer describing the Civil War will think of a wound-dressing as a red badge of social identity and return, but what is visually striking about Whitman's rendering of the idea is the extravagance and multiplicity of the covering gesture. The wound-dressing, for Whitman, occurs not as single surface, but as a sequence of folds or layers surrounding the suffering body. The covering cloth of the bandage, laid against the patient's skin, is repeated at a series of intervals moving out from the body-repeated, first, in the "drapery of white curtains" (58) hung around the patient's cot; repeated again, at a further remove from the body, in the expansive covering cloth of the hospital tent itself; and repeated, at last, in "the melancholy, draperied night above, and around" (47) that completes, and infinitely extends, the densely woven work of shelter.

The similarity of these acts of caring to the practice of writing is reflected in Whitman's emphasis on the nurse's own body. The physical posture of the nurse, in a phrase that appears frequently, is that of one bending down and over the white face of a patient. "An old man bending" is the opening phrase of "The Wound-Dresser"; the speaker in "A March in the Ranks" says, "I bend to the dying lad, his eyes open" (306); and in "Reconciliation," "I draw near, / Bend down and touch lightly ... the white face" (321). The posture itself becomes a kind of covering, a way of shielding the exposed body of the victim with the body of the nurse; and in this way the wound-dresser replicates the function of the bandages he applies. One sense of the importance of this position is that it records a physical change in the nurse, a bending from a vertical posture, that partially imitates the more radical physical change in the patient lying prone. By the end of "The Wound-Dresser," the nurse's body, with its pain "deep in my / breast" (311), partially reflects the soldier's own wounds. But at the same time the posture reminds us that the nurse's physical position relative to the wounded patient is exactly mimetic of the writer's or reader's physical position relative to the written text-bending over and looking at an exposed, upturned, horizontal surface. When the speaker in "The Wound-Dresser" reminds the reader of this position - "With hinged knees returning I enter the doors, (while for you up there, / Whoever you are, follow ... .)"-or when the speaker in "How Solemn as One by One" says, "I glance upward out of this page studying you, dear friend, / whoever you are" (322), our sense of being above and bending over the representation of a patient exactly matches the position of the nurse above and bending over an actual one. Medical and literary attention are shown to be close versions of one another in these moments. In both cases, the wounded body, originally construed in terms of what it is missing, in terms of its diminishment and 
negation, regains a sense of presence and completeness by the attention it can compel. To be located in physical space, as the terms "above" and "below" imply, is to regain a place and a presence, and so to be rescued from "the painful absence" of the wound, a rescue dependent on the healing gaze of the wound-dresser, the reader, and the poet himself.

In many ways, Williams's representations of medical care closely follow Whitman's. There is the same emphasis on the silence and inarticulateness of the suffering patient, on the disfiguring effects of disease, on the mutually soothing effects of sympathy, and most importantly, on the relationship between writing and medicine as similar acts of public signification. In relating eccentric and incoherent physical symptoms to a disease, the doctor's diagnosis, like the wound-dresser's gifts, re-establishes disrupted patterns of coherence. When swollen limbs and inflamed skin are related to a constellation of signs called "erysipelas"; or when, from bowed and misshapen legs the physician is able to read "rickets," the body's deeply private pain is shown to cohere, through the unifying medical code, with others who share the same distress. The diagnosis is an assurance of determinate meanings, predictable patterns, the body's own legibility. Again and again in Williams's work, we witness the making public of what was otherwise hidden, silent, private, or disguised. Although the task for Williams is not to re-invest the body with meaningful signs (with bandages, with gifts of raspberries) but to read the compelling if yet incoherent signs already present, both poets nonetheless share the same emphasis on the public nature of medical attention.

The important difference is that where Whitman imagines this attention as a covering, for Williams it is more often an exposure, an opening up and entry into the private space of another person-a person from a class, nationality, and gender different from the doctor. Just as the physical body of the wound-dresser bending over a patient recalls and imitates the constitutive act of covering for Whitman, the physician's physical entry into the houses and bedrooms of his patients becomes a version of the more radical opening - of a mouth ("The Use of Force"), a womb ("A Night in June"), a chest ("Old Doc Rivers"), or a skull ("Jean Beicke")-that will follow from and repeat that entrance. The typical beginning of these stories is, appropriately, a house call, an act that brings the doctor inside, and that in some way announces and exposes private space. At the end of "A Face of Stone," after agreeing to accept the doctor's pills (which is essentially to accept his reading of her body, his way of ordering her world), the Polish patient's idiomatic English registers this acceptance in a phrase suggesting deeply personal surrender: "They're pretty big pills, I said. Look, they're green. That's the coating so they won't dissolve in your stomach and upset your digestion. . . . She looked at them again. Then for the first time since I had known her a broad smile spread all over her face. Yeah, she said, I swallow him."5

It is the doctor in Williams's stories, not the patient, as in Whitman, who is brought in from the outside, and Williams's attention to entrance is essen- 
tially attention to the separateness of the spaces of his patients, the boundaries of their houses and of themselves. The fact that so many of the injuries in the stories are skin diseases-burns in "The Paid Nurse," acne in "The Girl with a Pimply Face," erysipelas in "Danse Pseudomacabre" -is expressive of Williams's concern with edges, with the acutely evident because painfully evident physical borders of someone else. To the extent that crossing into the space of a patient is an act of violence, "the use of force" (as it is also in "Old Doc Rivers" when Millken's appendectomy is done without effective anesthesia, or when Rivers's attempt to incise an abscess is more like a knife attack than surgery), Williams intensifies the sense of what he calls in Spring and All "[a] world detached . . . sufficient to itself, removed from him (as it most certainly is) with which he has bitter and delicious relations and from which he is independent" (121).

To emphasize the act of entrance is to show that health in the medical stories, like imagination in Spring and All, depends on a moment of interruption and discontinuity. For what is consistent for Williams's patients is their pain. The disturbing and often violent entrance of the physician is justified and desirable precisely because it is an interruption in the all too familiar continuity of rickets, or acne, or rheumatism, or labor. The renewal of the mind's imagination as well as the body's health follows from this crossing over from the outside, this "transposition," as. Williams calls it in Spring and All, "into another medium" (150). The entrance of spring in the first poem of this collection, like the entrance of the physician in the medical stories, is an event of active interference. The "stark dignity of / entrance" (96) interrupts not only the familiar wind of a winter landscape but a familiar way of seeing that landscape. The "stiff curl of wildcarrot leaf" (95) intervenes in the broadly ranging "all along the road" way of seeing that characterizes the poem's opening stanzas. By turning the reader's gaze first down and then into the landscape, the poem actively models "the profound change" (95) it would appear only to describe. It is in this sudden shift to a new perceptual register that Williams locates the optimism of his practice and of his poems. Where Whitman seeks to reconnect the patient to routine habits of perception, and imagines the poem as a means to that reconnection and reunion, Williams seeks to "disconfirm" such habits, to defamiliarize them, and to show that health and imagination are always unpredictable, always unrecognizable, and as curious and foreign as the bodies of the women he treats.

\section{University of California, Berkeley}

\section{NOTES}

1 Walt Whitman, Specimen Days, in Prose Works 1892, ed. Floyd Stovall (New York: New York University Press, 1963), 1:100-101. Subsequent quotations from Specimen Days are taken from this edition and cited in the text by page number. 
2 Walt Whitman, Leaves of Grass: Comprehensive Reader's Edition, ed. Harold Blodgett and Sculley Bradley (New York: New York University Press, 1965), 306. Subsequent quotations from Leaves of Grass are taken from this edition and cited in the text by page number.

3 William Carlos Williams, Spring and All, in Imaginations, ed. Webster Schott (New York: New Directions, 1970), 150. Subsequent quotations from Spring and All are cited in the text by page number.

4 For a further discussion of this effect as a consequence of physical pain see Elaine Scarry, The Body in Pain: The Making and Unmaking of the World (New York: Oxford University Press, 1985), 3-59.

5 William Carlos Williams, "A Face of Stone," in The Doctor Stories, compiled by Robert Coles (New York: New Directions, 1984), 87. Subsequent quotations from The Doctor Stories are cited in the text by page number. 